\title{
IOT Based LPG Cylinder Monitoring System
}

\author{
Lokesh Chandak ${ }^{1}$, Aditya Kolhe ${ }^{1}$, Sathak Shirke ${ }^{1}$, Prof. Suresh Kurumbanshi², \\ Prof. Shashikant Patil ${ }^{2 *}$ \\ ${ }^{1}$ B.Tech Mechatronics, NMIMS University, Shirpur Campus \\ ${ }^{2}$ EXTC Department, NMIMS University, Shirpur Campus
}

*Corresponding Author: Prof. Shashikant Patil, EXTC Department, NMIMS University, Shirpur Campus, India.

\begin{abstract}
L P G$ Cylinders are widely used in Indian Subcontinent. The demand for LPG Cylinder is increasing with time. It was used widely in Urban and sub-urban areas, but in past 5-10 years the demand has reached in rural areas also. Similarly, the demand of LPG Cylinder has increased in the Industrial Sector. Liquid petroleum gas is highly flammable gas. With the increase of usage of LPG Cylinders, there has been a rise in accidents pertaining to gas leakages. Leakage of this gas raises risk of building fire, suffocation and explosion.

There have been many accidents due to explosion of LPG cylinders and in some of circumstances it is due to negligence of gas leakage. Arduous and diligent work is required to monitor gas leakages all the time. In view to address above problem, IOT system is proposed which diligently monitors the gas leakages with great precision \& accuracy. Whenever there is any gas leakage, the MQ-6 gas sensor will sense it and the corresponding alarm circuitry will be activated. Also the SMS will be sent to the customer. Another major predicament faced by the users of LPG Cylinders is untimely exhaustion of gas cylinder. It continuously monitors and displays the weight of the LPG cylinder. This will ultimately help the customer knowing when to replace the cylinder.
\end{abstract}

Keywords: IOT, MQ-6, Real Time, Node-MCU, Propane and Butane Gas..

\section{INTRODUCTION}

LPG is one of the clean fuel. It is most widely being used in India. It is being used for household purposes as well as for industrial purposes also. In case of household use it is mostly used in kitchen for cooking, whereas in case of industrial purpose it is being used in various industrial processes such as gas cutting, gas welding, metallurgical industries, steel plants, glass cutting, pharmaceutical industries and many more. Apart from this the gas cylinders are also used in schools, colleges, hospitals, hotels and restaurants and many other places. In the past years the demand for use of LPG have increased sustainably and will continue to rise. But with the increase in demand of use of LPG the rate of accidents caused due to it have also increased in the past few years. The majority of the accidents are due to the explosion of LPG cylinder. But, sometimes very small quantity of gas leakage is unnoticed and is responsible for the further major accident. This paper discusses the solution to it. The other problem which is faced by the users of LPG cylinder is the untimely emptying of the cylinder. We have used IoT (Internet of Things) in this project. It is the cloud service which will gather and store the data.

\section{ARCHITECTURE}

\subsection{Gas Leakage Detection Circuit}

In this module the Gas leakage system is discussed. The block diagram for the same is shown below. The system comprises of MQ-6 gas sensor, Node-MCU ESP8266, LED's and Buzzer. 


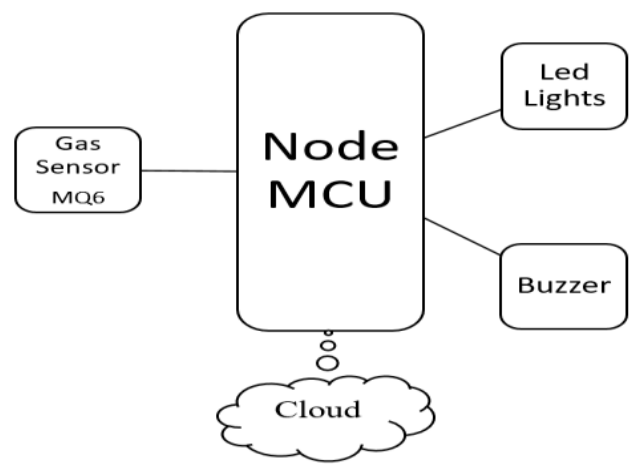

Fig1. Block diagram of Gas Leakage system

\subsubsection{MQ6 Gas Sensor}

The gas cylinders mostly contains LPG. The main constituents of LPG are propane and butane gas. The sensor available to detect this gases is MQ-6 and MQ-5. But MQ-6 sensor detects only LPG and butane gas. So, we selected it. As it detects the gases which are the main constituent of cylinders, it will give precise and accurate reading. Moreover, this sensor has very rapid response to LPG gas. It has very small sensitivity for alcohol, smoke. It detects propane, iso-butane, LPG with very high sensitivity and accuracy. This sensor is stable, durable, has fast response, and can be used in simple drive circuit. It has analog output and wide detection range. This are the characteristics of the sensor.

It can detect the gas leakage having the ppm value between 200 to 10000 .

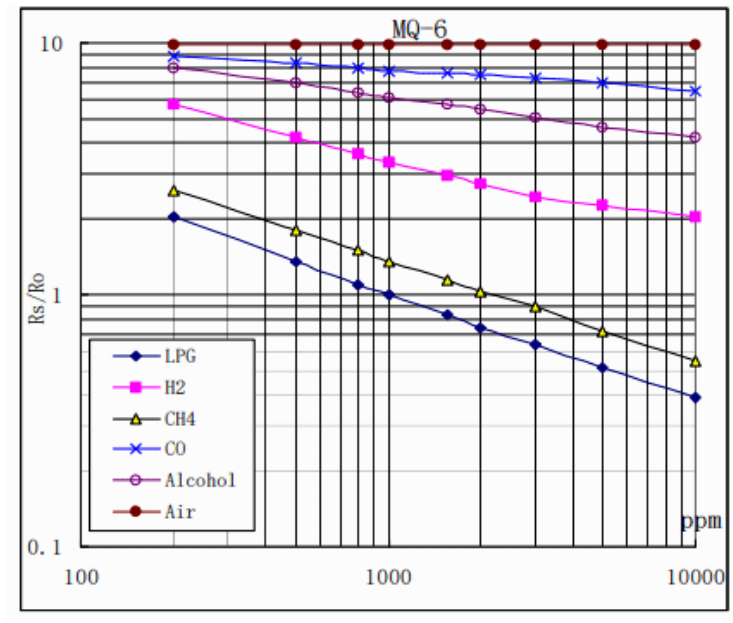

Fig2. ppm value graph of $M Q 6$ sensor

Hence, we can easily find the value of Ro by calibrating it in the fresh air. To find the value of Rs there is on formulae

$$
\mathrm{Rs}=\left(\frac{\mathrm{V}_{\mathrm{c}}}{\mathrm{V}_{\mathrm{RL}}}-1\right) \times \mathrm{R}_{\mathrm{L}}
$$

Now, we get the value of Rs and Ro. We can find the Rs/Ro and from the frame we find the ppm value

Corresponding to that ratio for the particular gas.

\subsubsection{Node-MCU ESP8266}

Node-MCU is the open source firmware which is developed for ESP8266 Wi-Fi chip. It has 30 pins. The ESP8266 requires 3.3V supply, so to ensure the proper supply it has built-in buck converter circuit, which converts the high- power supply into the desired power supply.

The GPIO (General Purpose Input Output) pins which are present on the chip can be used as either input pin or as output pin. This board can be programmed using the Arduino IDE software. It does not require any special software for it. 
In this project the Node-MCU will receive the data sensed by the gas sensor and it will send that data to cloud

\subsubsection{Buzzer}

The buzzer is an audio device. The main use of buzzer includes alarming for any danger. In this project we have used active buzzer. The main purpose for using buzzer in this project is to alarm the people for any leakage if there is any.

\subsubsection{Led}

The led (Light Emitting Diode) is a semiconductor device which is used as light source. They are used as indicator lamps in many devices and nowadays they are being used for lighting.

In this project we have used 2 led's: red and yellow. When the gas concentration detected will be between 200 to $1000 \mathrm{ppm}$ the yellow led will glow and when the concentration detected will be above $1000 \mathrm{ppm}$ the red led will be activated

\subsection{Weight Monitoring System}

This is the second module of our project. It discusses about the weight monitoring system. This system comprises of Arduino UNO board, load cell and LCD display.

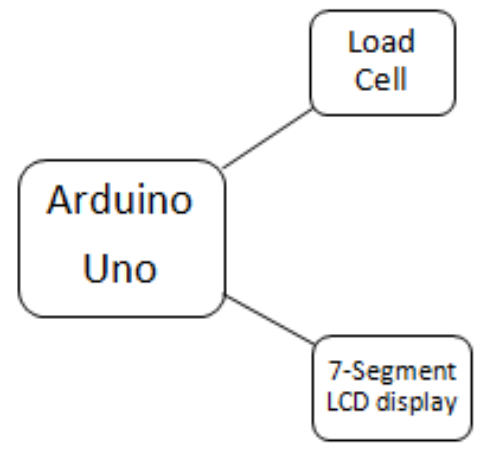

Fig3. Block diagram of weight monitoring system

\subsubsection{Arduino Uno}

In this proposed system the Arduino act as the brain of the system i.e. it will be used as a controller. The Arduino consist of 8-bit ATmega328 chip. It has 20 digital input/output pins, a $16 \mathrm{MHz}$ resonator, a USB connection, a power jack, an in-circuit system programming (ICSP) header, and a reset button.

The coding for Arduino UNO can be done in Arduino IDE software. Once Arduino IDE is installed on the computer, connect the board with computer using USB cable. Now open the Arduino IDE and choose the correct board by selecting Tools>Boards>Arduino/Genuino UNO and choose the correct Port by selecting Tools>Port.

The ATmega328 chip on Arduino UNO has a memory of 32KB. It also has $1 \mathrm{~KB}$ of EEPROM for reading and writing from EEPROM library. The programming for Arduino UNO can be done in Arduino IDE software.

\subsubsection{Load Cell}

Load cell is a sensor which converts a load into electrical signal. The electric signal can be current, voltage or frequency change depending on the circuit used. There are various types of load cell available. The load cell uses spring and strain gauge for measurement. The spring is the main structural component of load cell. It develops strain when the load is applied to load cell. The strain gauge works on the principle of change in resistance.

For this project we have selected the beam type load cell. The load cell is double bending beam type. It consists of four strain gauges in the Wheatstone configuration. The change in resistance of strain gauge will generate electric signal. Load cell are used in weight measuring system in aerospace, automotive and pharmaceutical industries on daily basis. The reason behind this is the characteristic of load cell. 
Some of the characteristic of load cell are they are highly precise, small influence due to temperature change, good fatigue characteristic, give linear measurement and not susceptible to external environment change.

\subsubsection{LCD Display}

LCD (Liquid Crystal Display) uses liquid crystal to produce visual image. It is a super thin display that is used in laptop and computer screens, tv's, mobile phones and portable video games. In this project we are using LCD display to display the weight measure by the load cell.

\section{WORKING}

The working of this project is classified into two modules. In the first module the working of gas leakage system is discussed. While in the second module the working of the load cell is explained.

\subsection{Gas Leakage Detection System}

The gas leakage detection system consists of Node-MCU ESP8266 module, MQ-6 gas sensor, a led and a buzzer.

The cloud service used is Thingspeak.com. This system will be placed at such a location such that there will be no disturbance for the detection of gas leakage. The preferred location will be near the gas stove. If the MQ-6 sensor finds that there is any concentration of gas in the surrounding environment, then it will sense it and will send a signal to Node-MCU. The module will process the signal and will activate the led or buzzer depending on the strength of the signal received. The maximum voltage to the sensor is $5 \mathrm{~V}$. When it detects the gas in the surrounding, the resistance of the sensor changes (increases or decreases) the voltage of the sensor. The signal generated by the sensor will depend on the voltage output of the sensor. Lower the voltage, stronger the signal generated.

We have calibrated the sensor accordingly, if the concentration of the gas detected is between 200-400 ppm then the led will be activated, and a SMS will be sent to the customer. If the concentration is above $400 \mathrm{ppm}$, then the buzzer will also be activated along with the led and the alert SMS will be sent. Each data will be uploaded to the cloud with the help of Node-MCU.

If the concentration of propane and butane is more than $1.8 \%$ to $10 \%$ in the surrounding air, then it is very dangerous. It is very likely to catch fire and it creates difficulty for breathing. So, we have kept it in mind and designed our system in such a way that it should detect every minute concentration and should help in preventing the further accidents.

\subsection{Weight Monitoring System}

This system consists of load cell, an Arduino module and an LCD screen. This system will be placed at the base of the cylinder or we design our own base for cylinder and place this system on it accordingly.

The load cell is used to measure the weight of the object placed over it. In this case it will measure the weight of the gas cylinder. Before it measures the weight and begins the monitoring it requires calibration. After the calibration is done it will measure the weight placed over it continuously. It gives the output in analog form. The load cell is calibrated and will display the readings on the LCD screen. Now, if the weight of the cylinder will be less than $19 \mathrm{~kg}$ the message displayed on the LCD stating the low weight of the cylinder and to refuel it or to order a new one. If the weight of the cylinder is below $14 \mathrm{~kg}$ then the message displayed on the LCD stating that the cylinder is empty.

When a new cylinder will be placed on the load cell, it will calibrate the new weight and then measure the weight. The above process will be repeated for every cylinder placed on the load cell.

\section{RESULTS}

Testing of gas leakage monitoring system \& weight of load cell carried out successfully on node MCU. 


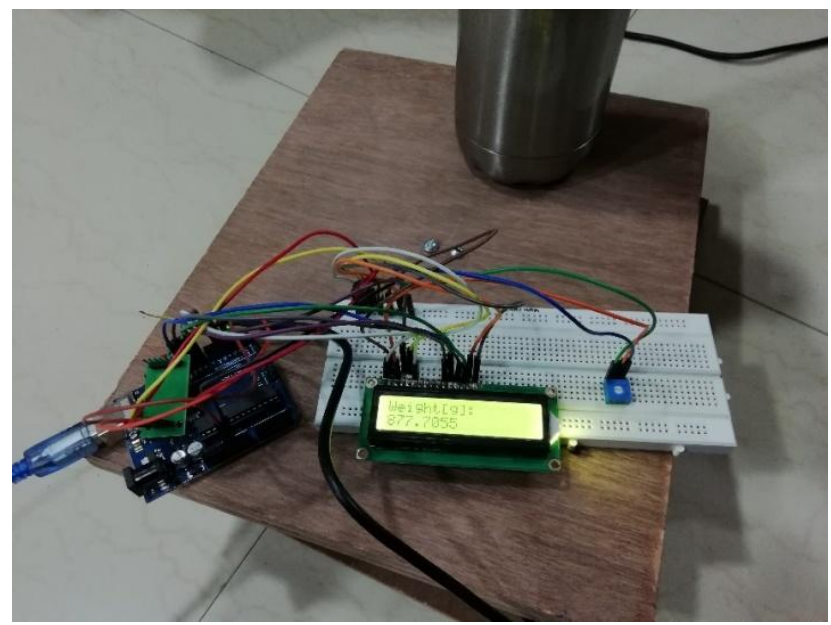

Fig4. Weight monitoring system

The weight is placed on the stand for the load cell and it's reading are observed. The reading given by the load cell is given in grams.

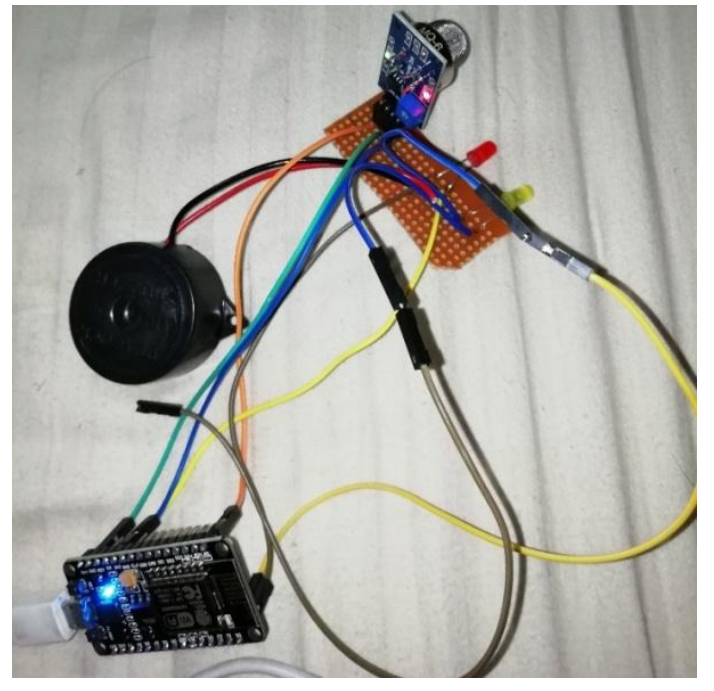

Fig5. Gas detection System

Here the Gas sensor is tested and the corresponding results were observed. Data was sent to the cloud. When the gas leakage is detected the LED glows and the Buzzer is turned on simultaneously

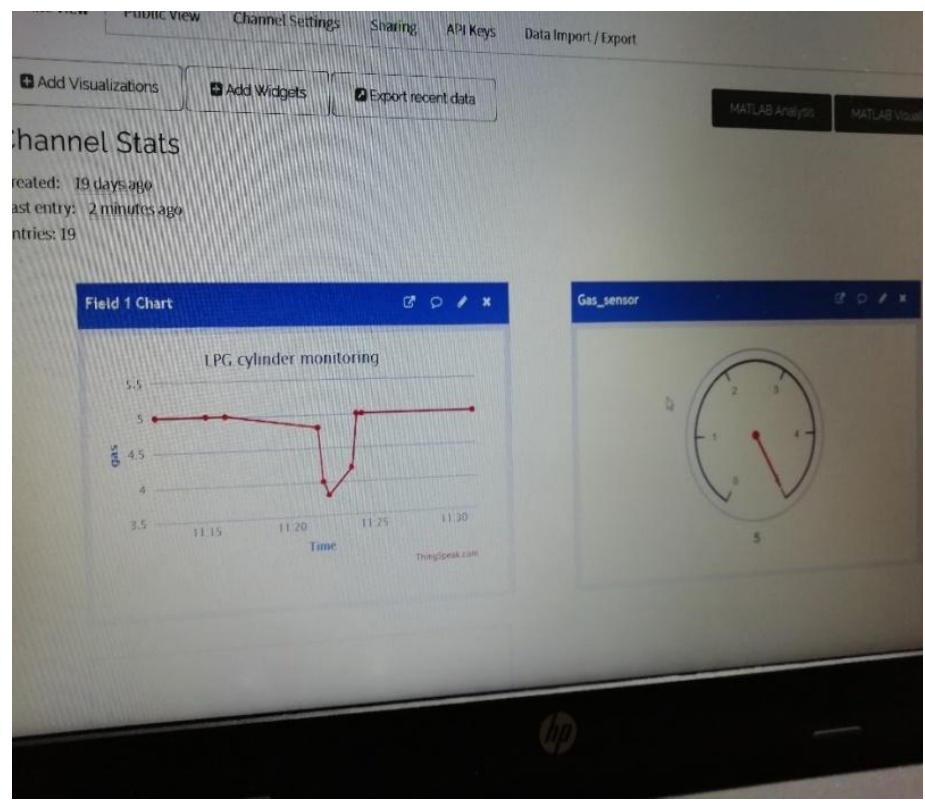

Fig6. Monitoring Data on Cloud 
The above figure shows the data which is stored on the cloud. The data is sent by the gas sensor with the help of Node-MCU. The graph indicates the date and time when the gas leaked and the table next to it will show the amount of gas leaked. The prototype of this proposed system was constructed and tested successfully. The sensor sense when there is any leakage and sends the SMS to customer and also turn on the buzzer simultaneously. This system also monitors the data continuously using cloud.

\section{CONCLUSION}

In this paper, we focus on designing a prototype for IoT based LPG cylinder monitoring system. The proposed system is cost-effective and it is real-time. It monitors gas leakage on continuous basis and displayed the weight and gas level on mobile. The customer will get the information about the leakage of LPG and if someone is present near his/her house at that particular time, they will be notified accordingly. IoT based system will send an alert message to users on their phones so that they will be more aware about the gas level \& leakage of LPG.

\section{Future SCOPE}

Major cities of India are pushing Smart Home application, gas monitoring system is a part of Smart Home application. Enhancing Industrial Safety using IoT. IoT turns drone into gas detection sensor. Another major future scope could be including a Automatic Shut-off device which will turn off the gas supply whenever it will detect any gas leakage. This system can be implemented in Industries, Hotels and wherever the LPG cylinders are used. This system can be used in industries involving applications such as Furnace, Boilers, Gas welding, Gas cutting, Steel Plants, Metallurgical industries, Food processing Industries, Glass Industries, Plastic industries, Pharmaceuticals, Aerosol manufacturing. As hospitals require to provide maximum possible safety to patients, this system can be used to keep track of all the cylinders used in it. Some of the cylinders used are Oxygen cylinder, Carbon dioxide cylinder, Nitrous oxide cylinder. As many students are naïve the risk of causing accidents is high. Hence, our system can also be used in schools, colleges. Many colleges have well established labs including chemistry lab and pharmaceutical labs where gas burners are used. Plenty of medical equipment requires gas cylinders.

\section{REFERENCES}

[1] Kumar Keshamoni, Sabbani Hemanth, "Smart Gas Level Monitoring, Booking and Gas Leakage Detector over IoT", IEEE 7th International Advance Computing Conference,2017.

[2] Chaitali Bagwe, Vidya Ghadi, Vinayshri Naik, Neha Kunte, "IOT Based Gas Leakage Detection System with Database Logging, Prediction and Smart Alerting- Review",March 2018.

[3] B. D. Jolhe, P. A. Potdukhe, N. S. Gawai, "Automatic LPG Booking, Leakage Detection And Real Time Gas Measurement Monitoring System", International Journal of Engineering Research \& Technology (IJERT) ,April 4, 2013.

[4] R.Naresh Naik, P.Siva Nagendra Reddy, S.Nanda Kishore, K.Tharun Kumar Reddy. "Arduino Based LPG gas Monitoring \& Automatic Cylinder booking with Alert System”, IOSR Journal of Electronics and Communication Engineering (IOSR-JECE), August 2016.

[5] S.Rajitha, T.SWAPNA, “A Security Alert System Using Gsm For Gas Leakage”, International Journal Of VLSI And Embedded Systems, 2012.

[6] Shruthi Unnikrishnan, Mohammed Razil, Joshua Benny, Shelvin Varghese and C.V. Hari,"LPG Monitoring and Leakage Detection System", IEEE WiSPNET, 2017

[7] Arun Raj, Athira Viswanathan, "LPG gas monitoring system", INTERNATIONAL JOURNAL OF INNOVATIVE TECHNOLOGY AND RESEARCH, Volume No.3, 2015.

[8] Https://Www.Projectsof8051.Com/Iot-lpg-leakage-detector-project/

[9] Https://Www.Projectsof8051.Com/Gsm-based-lpg-weight-and-lpg-leakage-detection-system/

[10] Https://Www.Survivingwithandroid.Com/2017/02/Build-iot-project-arduino-sensor-3-steps.Html

[11] https://www.engineersgarage.com/insight/how-gas-sensor-works

[12] https://instrumentationtools.com/load-cell-working-principle

[13] https://www.electronicwings.com/nodemcu/nodemcu-gpio-with-arduino-ide 
[14] https://components101.com/sensors/mq-6-gas-sensor-pinout-equivalent-datasheet

[15] https://www.hbm.com/en/6768/what-is-a-load-cell-and-how-does-a-load-cell-work/

[16] https://medium.com/@ cgrant/using-the-esp8266-wifi-module-with-arduino-uno-publishing-to-thingspeak$99 \mathrm{fc} 77122 \mathrm{e} 82$

Citation: Prof. Shashikant Patil, et.al, “IOT Based LPG Cylinder Monitoring System”, International Journal of Innovative Research in Electronics and Communications, 7(2), pp. 1-7. DOI: http://dx.doi.org/10.20431/2349-4050.0702001

Copyright: (c) 2020 Authors, This is an open-access article distributed under the terms of the Creative Commons Attribution License, which permits unrestricted use, distribution, and reproduction in any medium, provided the original author and source are credited. 